\title{
YES Portal
}

National Cancer Institute

\section{Source}

National Cancer Institute. YES Portal. NCI Thesaurus. Code C160686.

A web-based research intervention tool designed to collect and assess participants' toxicities and symptoms, as well as informational needs in between visits with their clinician. 